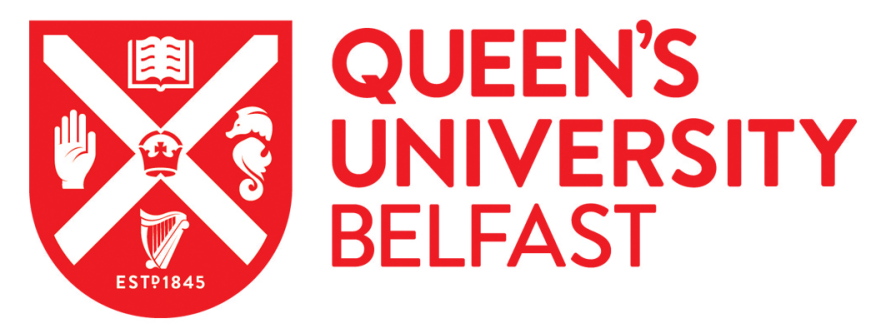

\title{
Association and liquid structure of pyridine-acetic acid mixtures determined from neutron scattering using a 'free proton' EPSR simulation model
}

McCune, J. A., Turner, A. H., Coleman, F., White, C. M., Callear, S. K., Youngs, T. G. A., Swadzba-Kwasny, M., \& Holbrey, J. D. (2015). Association and liquid structure of pyridine-acetic acid mixtures determined from neutron scattering using a 'free proton' EPSR simulation model. Physical Chemistry Chemical Physics, 17, 6767-6777. https://doi.org/10.1039/C4CP05746E

Published in:

Physical Chemistry Chemical Physics

Document Version:

Peer reviewed version

Queen's University Belfast - Research Portal:

Link to publication record in Queen's University Belfast Research Portal

\section{Publisher rights}

Copyright the authors

This article was firstly published by the Royal Society of Chemistry.

\section{General rights}

Copyright for the publications made accessible via the Queen's University Belfast Research Portal is retained by the author(s) and / or other copyright owners and it is a condition of accessing these publications that users recognise and abide by the legal requirements associated with these rights.

Take down policy

The Research Portal is Queen's institutional repository that provides access to Queen's research output. Every effort has been made to ensure that content in the Research Portal does not infringe any person's rights, or applicable UK laws. If you discover content in the

Research Portal that you believe breaches copyright or violates any law, please contact openaccess@qub.ac.uk. 


\title{
Association and liquid structure of pyridine-acetic acid mixtures de- termined from neutron scattering using a 'free proton' EPSR simula- tion model
}

\author{
Jade A. McCune, ${ }^{a}$ Adam H. Turner, ${ }^{a}$ Fergal Coleman, ${ }^{a}$ Caithlin M. White, ${ }^{a}$ Samantha K. Callear, ${ }^{b}$ \\ Tristan G. A. Youngs, ${ }^{b}$ Małgorzata Swadźba-Kwaśny ${ }^{a}$ and John D. Holbrey ${ }^{a *}$
}

Received Xth $X X X X X X X X X X 20 X X$, Accepted Xth $X X X X X X X X X 20 X X$

First published on the web Xth XXXXXXXXXX $200 X$

DOI: $10.1039 / b 000000 x$

The liquid structure of pyridine-acetic acid mixtures have been investigated using neutron scattering at various mole fractions of acetic acid, $\chi_{\mathrm{HOAc}}=0.33,0.50$, and 0.67 and compared to the structures of neat pyridine and acetic acid. Data has been modelled using Empirical Potential Structure Refinement (EPSR) with a 'free proton' reference model, which has no prejudicial weighting towards either the existence of molecular or ionised species. Analysis of the neutron scattering results shows the existence of hydrogen-bonded acetic acid chains with pyridine inclusions, rather than the formation of an ionic liquid by proton transfer.

\section{Introduction}

\section{Acid-base mixtures}

Our interest in ionic liquids lies in understanding structure and solvation. ${ }^{1}$ In particular, how the local environments of solutes dissolved in ionic liquids can be controlled and how this information can be used to modify reactive and extractive processes using ionic liquids.

In many cases the components present in ionic liquids can be defined without ambiguity e.g. aprotic ionic liquids and neutral solutes. For example, in the case of glucose dissolved in 1-ethyl-3-methylimidazolium acetate, ${ }^{2}$ studied as a model for cellulose dissolution in ionic liquids, the solution contains 1-ethyl-3-methylimidazolium cations, acetate anions and glucose. However, the structures of the species present can not always be so readily defined. Ionic liquids containing halometallate anions ${ }^{3}$ typically exhibit compositiondependent changes in anion speciation (eq. 1)

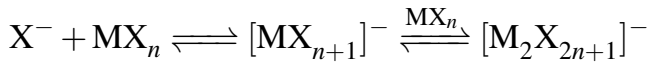

Similarly, in ionic liquids formed by proton transfer from acids to bases, hydrogen-bonded complex anions and cations, can be generated in addition to simple ions following the equilibria shown below: ${ }^{4}$

$$
\mathrm{H}-\mathrm{A} \underset{\mathrm{H}-\mathrm{A}}{\stackrel{\mathrm{Nu}}{\rightleftharpoons}}[\mathrm{Nu}-\mathrm{H}][\mathrm{A}-\mathrm{H} \cdots \mathrm{A}]
$$

a The QUILL Research Centre, School of Chemistry and Chemical Engineering, Queen's University Belfast, Belfast BT9 5AG, UK. Email: j.holbrey@qub.ac.uk

${ }^{b}$ Rutherford Appleton Laboratory, Chilton, Didcot, Oxon, OX11 0QX, UK.

$$
\begin{gathered}
{[\mathrm{Nu}-\mathrm{H}][\mathrm{A}-\mathrm{H} \cdots \mathrm{A}] \underset{\mathrm{H}-\mathrm{A}}{\stackrel{\mathrm{Nu}}{\rightleftharpoons}}[\mathrm{Nu}-\mathrm{H}][\mathrm{A}]} \\
{[\mathrm{Nu}-\mathrm{H}][\mathrm{A}] \underset{\mathrm{H}-\mathrm{A}}{\stackrel{\mathrm{Nu}}{\rightleftharpoons}}[\mathrm{Nu}-\mathrm{H} \cdots \mathrm{Nu}][\mathrm{A}]}
\end{gathered}
$$

Liquid acid-base mixtures, some of which are examples of ionic liquids and some of which are not, have been studied since the nineteenth century; Ramsay ${ }^{5}$ described the formation of a 'syrupy' liquid from combining picoline with citric acid, while Walden ${ }^{6}$ described the first study of the archetypal protic ionic liquid ethylammonium nitrate. The properties of pyridine-acetic acid mixtures were first reported as far back as 1934 and continue to be of interest. Non-ideal mixing of the liquids was observed, with bulk properties including density, viscosity, specific conductance and volume contraction displaying a maxima at $\chi_{\mathrm{HOAc}}=0.83$. Examples of these changes in viscosity and conductivity with $\chi_{\mathrm{HOAc}}$ are shown in Figure 1. 7,8

Swearingen and Heck initially attributed this behaviour to the formation of a 'compound' at $\chi_{\mathrm{HOAc}}=0.83$. In the $1950 \mathrm{~s}$, Venkatesan and Suryanarayana proposed full ionisation of acetic acid at $\chi_{\mathrm{HOAc}}<0.83$ to explain the increases in conductivity and $\mathrm{pH} .{ }^{8}$ More recently, low temperature ${ }^{1} \mathrm{H}$ and ${ }^{15} \mathrm{~N}$ NMR studies of pyridine-acetic acid solutions in $\mathrm{CDClF}_{2} /$ $\mathrm{CDF}_{3}$ identified the formation 1:1, 1:2, and 1:3 pyridineacetic acid aggregates, [py $\cdots$ HOAc], [py $\cdots$ HOAc $\cdots$ HOAc] and [py $\cdots$ HOAc $\cdots$ HOAc $\cdots$ HOAc], respectively, which slowly exchanged on the NMR time-scale ${ }^{9}$ with the degree of pyridine protonation increasing with the cluster size. Langner and Zundel reported the presence of weakly hydrogen-bonded 


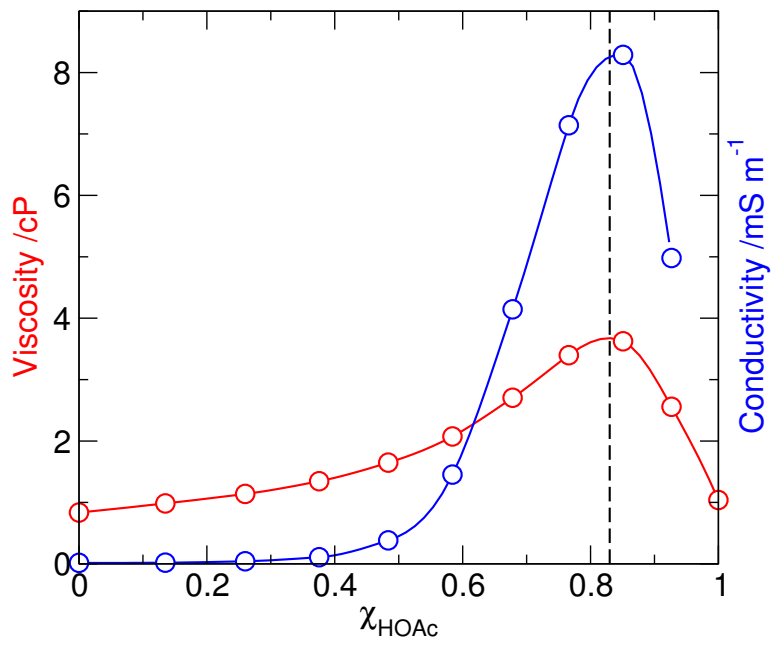

Fig. 1 The change in viscosity and specific conductivity with composition of pyridine-acetic acid mixtures at $30{ }^{\circ} \mathrm{C}$ (data replotted from Swearingen and co-workers ${ }^{7}$ ).

acid-base pairs between $\chi_{\mathrm{HOAc}}=0.17$ to 0.50 in chloroform solution, in equilibrium with free pyridine and acetic acid, identified by infrared spectroscopy. ${ }^{10,11}$ At $\chi_{\mathrm{HOAc}}=$ 0.17 , all acetic acid was reported to be complexed, as acidbase pairs ([Py $\cdots \mathrm{H}-\mathrm{OAc}])$ with no evidence for formation of $[\mathrm{Py}-\mathrm{H} \cdots \mathrm{Py}]^{+}$species that would be indicators of pyridine protonation.

Considering similar mixtures with slightly stronger bases, Johansson et al. ${ }^{12}$ reported that neat N-methylpyrrolidineacetic acid mixtures formed 'poor' protic ionic liquids with a low degree of ionicity, and that this varied with composition mirroring the properties of the pyridine-acetic acid system. They proposed that hydrogen-bonded complex anion clusters, $\left[\mathrm{Ac}_{n} \mathrm{H}_{(n-1)}\right]^{-}$, with greater acidity than 'free' acetic acid, were formed, explaining the observed non-stoichiometric maxima. Gas phase ab initio calculations showed that hydrogen-bonded acid-base pairs were more stable at $\chi_{\mathrm{HOAc}}=0.50$, whereas when $\chi_{\mathrm{HOAc}}>0.50$, anionic clusters stabilised by charge dispersion were preferred and consequentially lead to protonation of the base.

This picture, of ionic interactions stabilised by charge dispersion over hydrogen-bonded oligomeric carboxylic acid chains seems to be common both to the ionic liquid system of Johansson et al. ${ }^{12}$ and to the solution state NMR studies of pyridine-acetic acid from Golubev et al. ${ }^{9}$ Proton transfer in acid-base mixtures is a complex phenomenon, dependant on $\Delta \mathrm{p} K_{\mathrm{a}}$ between the acid and base, ${ }^{13}$ the hydrogen-bonding ability of the base, ${ }^{14}$ and on the acid-base ratio, $\chi_{\mathrm{HOAc}}$.

\section{'Free proton' model in neutron scattering}

The inherent structural complexity of liquids and glasses makes structural determination challenging. ${ }^{15}$ Neutron diffraction provides a powerful tool to investigate such disordered materials and the adoption of computational simulation methods, such the Empirical Potential Structure Refinement (EPSR) approach, ${ }^{16}$ makes analysis of atomically complex systems possible, even when all the individual correlation functions can not be explicitly obtained. ${ }^{17}$ However, as with any simulation techniques, it is possible to fit various arbitrary models to experimental data. In order to guide fitting to structurally and chemically sound outcomes, as much chemical information as possible needs to be included in the initial simulation models.

Many liquid systems have been successfully studied, including water, ${ }^{18}$ aqueous salts and surfactant solutions, ${ }^{19}$ inorganic molten salts ${ }^{20}$ and glasses, ${ }^{15,21}$ chemically 'simple' molecular liquids such as aromatic hydrocarbons, ${ }^{22}$ ethers and alcohols, ${ }^{23}$ carboxylic acids, ${ }^{24}$ and chemically more 'complex' ionic liquids. ${ }^{1,25,26}$ and ionic liquid solutions. ${ }^{2,27}$

In all studies of ionic liquids to-date, the ions have been treated as discrete species without taking possible equilibria into consideration. Even with protic alkylammonium nitrates, ${ }^{25}$ ionic descriptors $\left(\left[\mathrm{RNH}_{3}\right]^{+}\right.$and $\left.\left[\mathrm{NO}_{3}\right]^{-}\right)$have been used, an approach that is valid considering negligibly small dissociation constant for this ionic liquid (eq. 5 with $K_{\mathrm{d}}=$ $3.6 \times 10^{-3}$ at $298 \mathrm{~K}^{28}$ ):

$$
\left[\mathrm{EtNH}_{3}\right]\left[\mathrm{NO}_{3}\right] \stackrel{K_{\mathrm{d}}}{\rightleftharpoons} \mathrm{EtNH}_{2}+\mathrm{HNO}_{3}
$$

However, for the reasons discussed above, this approach cannot be adopted for weak acid-base mixtures because of uncertainties about the extent of proton transfer.

We decided to use neutron scattering to investigate the liquid structure of pyridine-acetic acid mixtures, employing EPSR to model the data. A deconstructed description of the acid-base mixtures $(\mathrm{H}-\mathrm{A}+\mathrm{Nu})$ incorporating only atomic connectivity information for two base components, $\mathrm{A}^{-}$and $\mathrm{Nu}$, were used. The acidic hydrogen was incorporated as a 'free proton' with no defined connectivity and was allowed to locate within the simulation model at positions driven by the iterative fit to the experimental data.

This approach was chosen to permit the simulation to respond to potential ionisation of acids and report directly on the the degree of proton transfer and resulting speciation within the liquids under investigation, and provide a versatile methodology for characterising complex fluids with labile protons. Botti et al. ${ }^{29}$ have previously applied this methodology to the study of acid speciation in concentrated $\mathrm{HCl}$ solutions; a system that is atomistically although not necessarily structurally simpler than those under consideration here. Experimental data was modelled using EPSR simulations con- 
<smiles>Cc1ccccc1</smiles><smiles>[1H][14CH](O)[14CH](O)O</smiles>

Fig. 2 Atom types used in the initial EPSR simulation models for pyridine and acetate.

taining, respectively, unconstrained $\mathrm{H}^{+},\left[\mathrm{H}_{3} \mathrm{O}\right]^{+}$or $\left[\mathrm{H}_{5} \mathrm{O}_{2}\right]^{+}$ (i.e. $\left.\left[\mathrm{H}\left(\mathrm{H}_{2} \mathrm{O}\right)_{2}\right]^{+}\right)$ions in addition to water and chloride. Comparable results were obtained in each case, indicating that the simpler free proton model was capable of evolving to reproduce the equivalent proton solvation environments as the more constrained models.

\section{Experimental}

Acetic acid, pyridine and acetic acid- $d_{4}$ were purchased from SigmaAldrich, deuteriated pyridine- $d_{5}$ was purchased from SigmaAldrich and Goss Scientific (Cambridge Isotope Laboratory). Deuterium substitution in each case was greater than $98 \%$.

Mixtures containing pyridine and acetic acid with $\chi_{\mathrm{HOAc}}=$ $0.33,0.50$ and 0.67 with differing combinations of deuteriated (D), protiated $(\mathrm{H})$ and 50:50 mixtures (H/D) of pyridine and acetic acid were prepared (Table 1). For comparison, data for neat pyridine $\left(\chi_{\mathrm{HOAc}}=0.00\right)$ and acetic acid $\left(\chi_{\mathrm{HOAc}}=1.00\right)$ were also collected for fully protiated, deuteriated and 50:50 mixtures. Densities of the fully protiated pyridine-acetic acid mixtures were measured using an Anton Paar DMA 4500 densitometer giving densities consistent with literature values. ${ }^{7}$ These elemental compositions and densities were also consistent with the observed total neutron scattering cross sections for each sample in the SANDALS experiments.

Neutron scattering data were collected on the twenty three samples (Table 1) using the SANDALS spectrometer at the ISIS pulsed neutron and muon source at the Rutherford Appleton Laboratory, UK. The instrument has a wavelength range of $0.05-4.5 \AA$, and data were collected over a $Q$ range from $0.05-50 \AA^{-1}$. Each sample was contained in 'null scattering' $\mathrm{Ti}_{0.68} \mathrm{Zr}_{0.32}$ flat plate cells with internal geometries of $1 \times 35 \times 35 \mathrm{~mm}$ and a wall thickness of $1 \mathrm{~mm}$. During measurements, the cell was maintained at a temperature of $298 \mathrm{~K}$ using a recirculating heater (Julabo FP50). Measurements were made on each of the empty sample holders, the empty spectrometer, and a $3.1 \mathrm{~mm}$ thick vanadium standard sample for the purposes of instrument calibration and data normalisation.

Data reduction was performed using GUDRUN, ${ }^{30}$ to produce a differential scattering cross section for each experi-
Table 1 Experimental sample compositions, indicating the mole fraction acetic acid $\left(\chi_{\mathrm{HOAc}}\right)$ and pyridine:acetic acid ratio.

\begin{tabular}{llcc}
\hline & $\begin{array}{l}\chi_{\text {HOAc }} \\
\text { (pyridine:acid ratio) }\end{array}$ & Pyridine & Acetic acid \\
\hline $\mathbf{1}$ & 0.00 & $\mathrm{D}$ & \\
$\mathbf{2}$ & & $\mathrm{H} / \mathrm{D}$ & \\
$\mathbf{3}$ & & $\mathrm{H}$ & \\
\hline $\mathbf{4}$ & $0.33(1: 2)$ & $\mathrm{D}$ & $\mathrm{D}$ \\
$\mathbf{5}$ & & $\mathrm{D}$ & $\mathrm{H} / \mathrm{D}$ \\
$\mathbf{6}$ & & $\mathrm{H} / \mathrm{D}$ & $\mathrm{D}$ \\
$\mathbf{7}$ & & $\mathrm{D}$ & $\mathrm{H}$ \\
$\mathbf{8}$ & & $\mathrm{H}$ & $\mathrm{D}$ \\
\hline $\mathbf{9}$ & $0.50(1: 1)$ & $\mathrm{H}$ & $\mathrm{D}$ \\
$\mathbf{1 0}$ & & $\mathrm{H} / \mathrm{D}$ & $\mathrm{D}$ \\
$\mathbf{1 1}$ & & $\mathrm{D}$ & $\mathrm{D}$ \\
$\mathbf{1 2}$ & & $\mathrm{D}$ & $\mathrm{H} / \mathrm{D}$ \\
$\mathbf{1 3}$ & & $\mathrm{D}$ & $\mathrm{H}$ \\
$\mathbf{1 4}$ & & $\mathrm{H} / \mathrm{D}$ & $\mathrm{H} / \mathrm{D}$ \\
$\mathbf{1 5}$ & & $\mathrm{H}$ & $\mathrm{H}$ \\
\hline $\mathbf{1 6}$ & $0.67(2: 1)$ & $\mathrm{D}$ & $\mathrm{D}$ \\
$\mathbf{1 7}$ & & $\mathrm{D}$ & $\mathrm{H} / \mathrm{D}$ \\
$\mathbf{1 8}$ & & $\mathrm{D}$ & $\mathrm{H}$ \\
$\mathbf{1 9}$ & & $\mathrm{H} / \mathrm{D}$ & $\mathrm{H} / \mathrm{D}$ \\
$\mathbf{2 0}$ & & $\mathrm{H}$ & $\mathrm{H}$ \\
\hline $\mathbf{2 1}$ & 1.00 & & $\mathrm{D}$ \\
$\mathbf{2 2}$ & & & $\mathrm{H} / \mathrm{D}$ \\
$\mathbf{2 3}$ & & & $\mathrm{H}$ \\
\hline
\end{tabular}

mental sample. The experimental sample densities and scattering levels were consistent with the actual isotopic compositions of the samples. Calibration and background subtraction for single atom scattering was made to produce a differential scattering cross section for each sample. Data from the neutron diffraction experiments was analysed using the Empirical Potential Structure Refinement (EPSR) program. ${ }^{16,31}$ The experimental total structure factors, $\mathrm{F}(Q)$, were extracted from the neutron scattering data for each of the isotopically distinct samples at each composition. These were used to build and refine three dimensional models of the liquid structure consistent with the experimental data using EPSR for the two pure liquids (pyridine and acetic acid, $\chi_{\mathrm{HOAc}}=0.00$ and $1.00 \mathrm{re}-$ spectively) and for the three mixtures at $\chi_{\mathrm{HOAc}}=0.33,0.50$, and 0.67. The EPSR approach consists of a Monte Carlo simulation, using Lennard-Jones potentials with atom-centred point charges that are combined with basic information about the structure of the atoms or molecules present in the system and total atomic densities of the system to constrain the model in a chemically and physically reliable manner. By comparing the differences between calculated and experimental structure factors in $Q$-space for data sets, an empirical perturbation po- 
Table 2 Lennard-Jones well depth $(\varepsilon)$, range $(\sigma)$, and charge $(q)$ parameters used for the reference potential of the Empirical Potential Structure Refinement model.

\begin{tabular}{lllr}
\hline Atom type & $\varepsilon\left(\mathrm{kJ} \mathrm{mol}^{-1}\right)$ & $\sigma(\AA)$ & $q(\mathrm{e})$ \\
\hline Pyridine & & & \\
\hline $\mathrm{N}$ & 0.500 & 3.25 & -0.2300 \\
$\mathrm{H}_{1}$ & 0.200 & 2.40 & 0.0500 \\
$\mathrm{C}_{1}$ & 0.500 & 3.50 & 0.0460 \\
$\mathrm{H}_{2}$ & 0.200 & 2.40 & 0.0320 \\
$\mathrm{C}_{2}$ & 0.500 & 3.50 & -0.0150 \\
$\mathrm{C}_{3}$ & 0.500 & 3.50 & -0.0280 \\
$\mathrm{H}_{3}$ & 0.200 & 2.40 & 0.0320 \\
\hline Acetate & & & \\
\hline $\mathrm{O}$ & 0.210 & 2.96 & -0.2750 \\
$\mathrm{H}_{\mathrm{A}}$ & 0.200 & 1.60 & 0.0650 \\
$\mathrm{C}_{\mathrm{A} 1}$ & 0.066 & 3.50 & -0.2525 \\
$\mathrm{C}_{\mathrm{A} 2}$ & 0.105 & 3.75 & 0.1075 \\
\hline${ }^{\prime}$ Free' proton & \multicolumn{3}{|}{} \\
\hline H & 0.100 & 0.60 & 0.5000 \\
\hline
\end{tabular}

tential is determined. This is combined with the reference potential used as the new potential for simulations, iteratively driving the simulation model towards agreement with experimental data.

All the EPSR simulation models were refined against the experimental data over the full data range $\left(Q=0.1-50 \AA^{-1}\right)$. A maximum amplitude in the non-parameterised empirical potential of $30 \mathrm{~kJ} \mathrm{~mol}^{-1}$ was allowed in addition to the reference potential. Within the EPSR simulations, pyridine was modelled using a simple molecular description while acetic acid was described using the 'free proton' description: as an acetate anion and unconstrained proton. Atom types for pyridine and acetate were defined based on their unique positions in the molecular skeleton of the two moieties, as shown in Figure 2. The full parameters of the reference potential used, derived from OPLS-AA parameters, with charges scaled by 0.50 , are given in Table 2. The free proton was assigned initial parameters of $\varepsilon=0.100 \mathrm{~kJ} \mathrm{~mol}^{-1}$ and $\sigma=0.60(\AA)$ in the reference potential in order to inhibit location of unparameterised hydrogens on top of oxygen atoms during equilibration of simulation models. The charges initially determined for isolated gas phase ions were deemed too high to adequately represent a condensed phase. Scaling down charges has been shown to be necessary to accurately represent liquid structure in ionic liquids ${ }^{26,32}$ and the reduced charges used here are comparable in magnitude to those used by Imberti and Bowron ${ }^{24}$ for their molecular acetic acid reference potential. Interatomic distance constraints used to define the basic molecular geometry of the pyridine and acetate structures within the model, obtained from $a b$ initio minimised geometry of the acetate anion
Table 3 Intramolecular bond distance $(\AA)$ and bond-angle $\left({ }^{\circ}\right)$ constraints used to define the basic structures of pyridine and acetate anion in the initial EPSR simulation model.

\begin{tabular}{llll}
\hline Bond Distance & $(\AA)$ & Bond Angle & $\left(^{\circ}\right)$ \\
\hline Pyridine & & & \\
\hline $\mathrm{N}-\mathrm{C}_{1}$ & 1.356 & $\mathrm{C}_{1}-\mathrm{N}-\mathrm{C}_{1}$ & 120.00 \\
$\mathrm{H}_{1}-\mathrm{C}_{1}$ & 1.080 & $\mathrm{~N}-\mathrm{C}_{1}-\mathrm{H}_{1}$ & 120.00 \\
$\mathrm{C}_{1}-\mathrm{C}_{2}$ & 1.450 & $\mathrm{~N}_{-}-\mathrm{C}_{1}-\mathrm{C}_{2}$ & 122.00 \\
$\mathrm{H}_{2}-\mathrm{C}_{2}$ & 1.080 & $\mathrm{H}_{1}-\mathrm{C}_{1}-\mathrm{C}_{2}$ & 120.00 \\
$\mathrm{C}_{2}-\mathrm{C}_{3}$ & 1.435 & $\mathrm{C}_{1}-\mathrm{C}_{2}-\mathrm{H}_{2}$ & 120.00 \\
$\mathrm{C}_{3}-\mathrm{H}_{3}$ & 1.080 & $\mathrm{C}_{1}-\mathrm{C}_{2}-\mathrm{C}_{3}$ & 120.30 \\
& & $\mathrm{H}_{2}-\mathrm{C}_{2}-\mathrm{C}_{3}$ & 120.00 \\
& & $\mathrm{C}_{2}-\mathrm{C}_{3}-\mathrm{C}_{2}$ & 115.90 \\
& & $\mathrm{C}_{2}-\mathrm{C}_{3}-\mathrm{H}_{3}$ & 122.05 \\
\hline Acetate & \multicolumn{3}{|}{} \\
\hline $\mathrm{H}_{\mathrm{A}}-\mathrm{C}_{\mathrm{A} 1}$ & 1.090 & $\mathrm{H}_{\mathrm{A}}-\mathrm{C}_{\mathrm{A} 1}-\mathrm{C}_{\mathrm{A} 2}$ & 111.40 \\
$\mathrm{C}_{\mathrm{A} 1}-\mathrm{C}_{\mathrm{A} 2}$ & 1.554 & $\mathrm{C}_{\mathrm{A} 1}-\mathrm{C}_{\mathrm{A} 2}-\mathrm{O}$ & 115.30 \\
$\mathrm{C}_{\mathrm{A} 2}-\mathrm{O}$ & 1.234 & $\mathrm{O}^{-} \mathrm{C}_{\mathrm{A} 2}-\mathrm{O}$ & 129.50 \\
& & $\mathrm{H}_{\mathrm{A}}-\mathrm{C}_{\mathrm{A} 1}-\mathrm{H}_{\mathrm{A}}$ & 107.70 \\
\hline & & & \\
\hline & &
\end{tabular}

Table 4 Details of the size of the EPSR simulations boxes used.

\begin{tabular}{llll}
\hline $\begin{array}{l}\text { Mole Fraction } \\
\left(\chi_{\mathrm{HOAc}}\right)\end{array}$ & $\mathrm{N}_{i}^{a}$ & $\begin{array}{l}\text { box size, } n \\
/ \AA^{b}\end{array}$ & $\begin{array}{l}\text { Number density } \\
\text { /atoms } \AA^{-3}\end{array}$ \\
\hline 0.00 & 500 & 40.59 & 0.008223 \\
0.33 & 800 & 42.57 & 0.007776 \\
0.50 & 900 & 41.67 & 0.007878 \\
0.67 & 1000 & 40.26 & 0.008272 \\
1.00 & 1200 & 39.96 & 0.007520 \\
\hline
\end{tabular}

$a \overline{\text { Number of independent groups in simulation box (pyridine }}$ + acetate + proton $),{ }^{b}$ cubic simulation box of size

$$
n \times n \times n \AA \text {. }
$$

using GAMESS-US ${ }^{33}$ at the MP2/6-31G(d) level of theory, are summarised in Table 3.

Simulations were equilibrated over $c a$. 2000-3000 cycles before accumulating and averaging data. The EPSR refinements, in each case, were initialised using an equilibrated Monte Carlo simulation containing approximately 500-600 molecular moieties (pyridine and acetate) with an appropriate number of protons to achieve charge neutrality. Total number of pyridine, acetate, and protons and size of each simulation box, corresponding to the experimentally determined molecular densities of the fully protiated mixtures are detailed in Table 4. Centre of mass radial distribution functions were calculated using the SHARM routines within EPSR. 


\section{Results and Discussion}

Neutron diffraction data were collected for liquid samples of acetic acid, pyridine, and pyridine-acetic acid mixtures, at three compositions $\chi_{\mathrm{HOAc}}=0.33,0.50$ and 0.67 , with a range of H/D substitutions as detailed in Table 1.

Data was modelled using EPSR and good fits between the experimental and EPSR simulated structure factors were obtained in each case. Figures 3 and 4 show comparisons of experimental and simulated $\mathrm{S}(Q)$ data and the corresponding Fourier transforms to real space $\mathrm{g}(r)$ for each of the isotopically distinct experimental mixtures. From the resulting simulation models, centre-of-mass radial distribution functions (RDFs) for acetic acid-acetic acid, pyridine-acetic acid, and pyridine-pyridine were calculated (Figure 5).
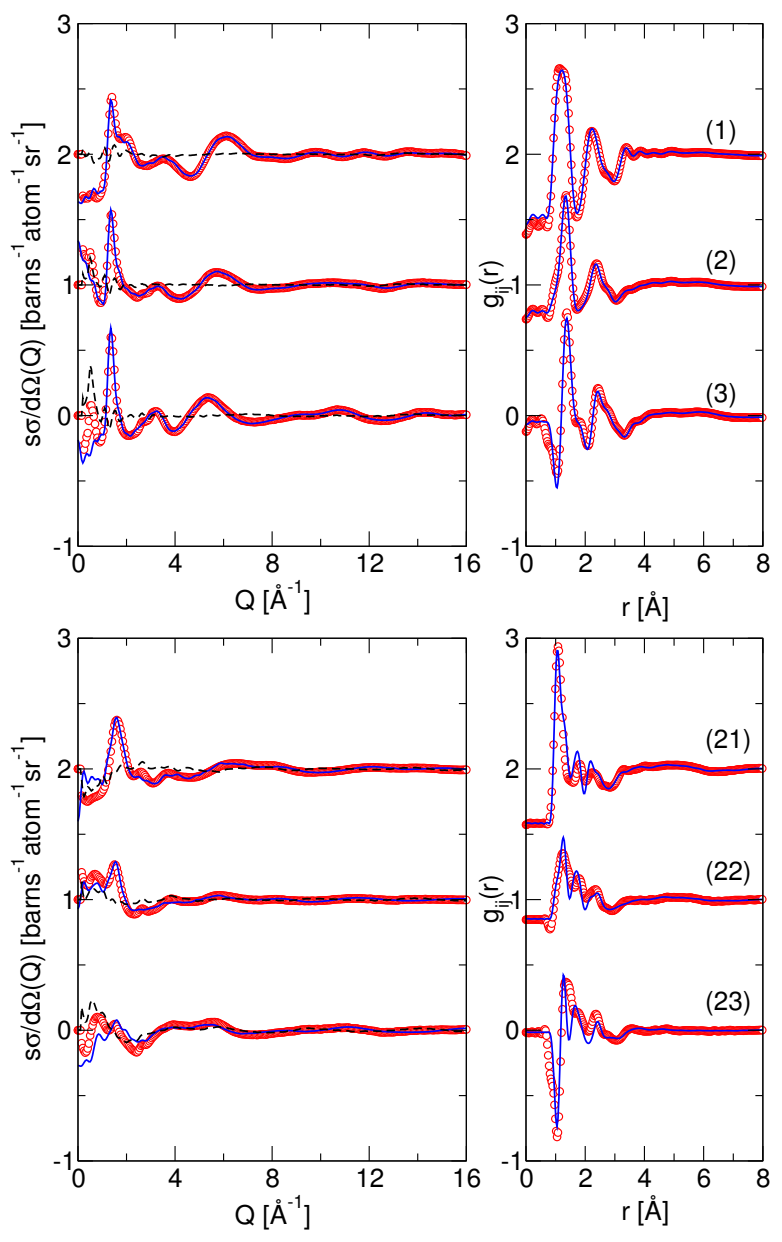

Fig. 3 Experimental $\mathrm{S}(Q)$ data (symbols), EPSR models for the data (lines) and residual differences between simulated and experimental data (dashed lines) (left), and the Fourier transform to real space $\mathrm{g}(r)$ (right) for pyridine (top) and acetic acid (bottom). Labels represent the experimental compositions shown in Table 1.
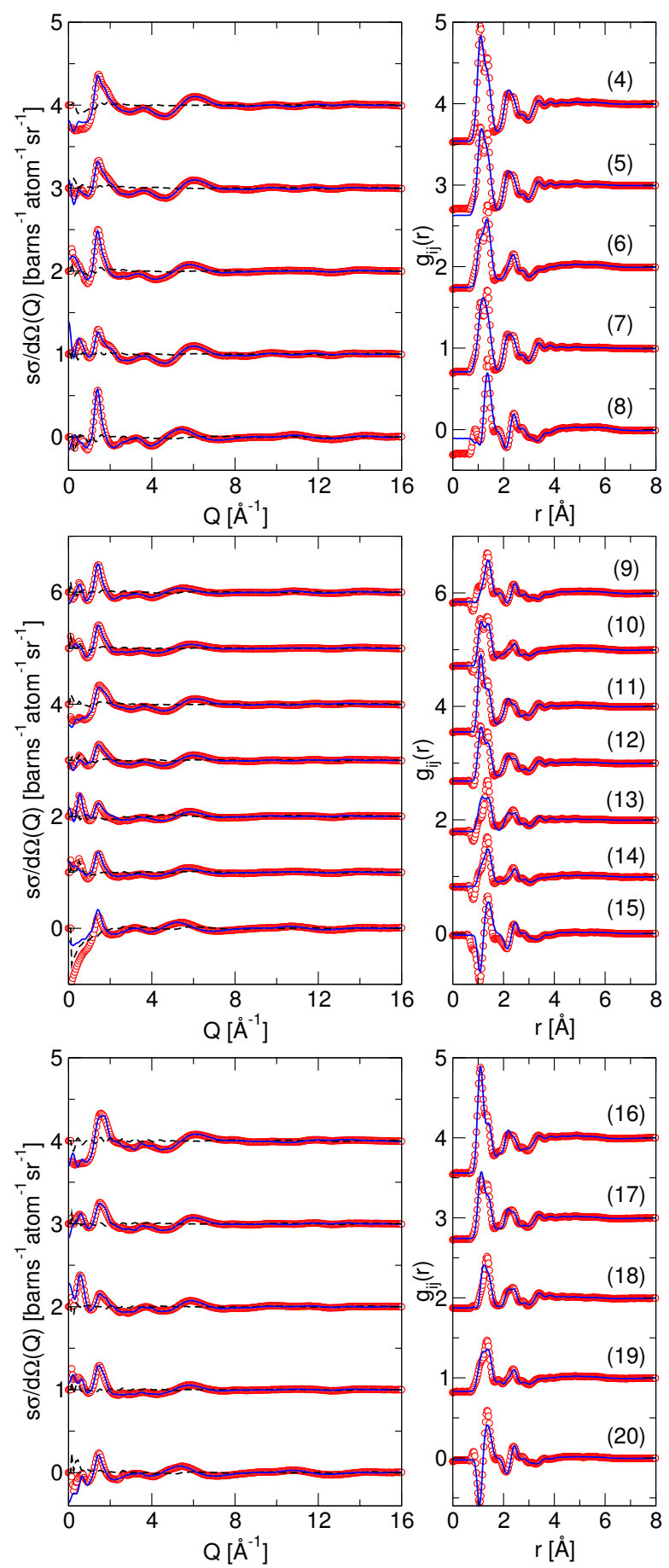

Fig. 4 Experimental $\mathrm{S}(Q)$ data (symbols), EPSR models for the data (lines) and residual differences between simulated and experimental data (dashed lines) (left), and the Fourier transform to real space $\mathrm{g}(r)$ (right) for the pyridine-acetic acid mixtures: $\chi_{\mathrm{HOAc}}=0.33$ (top), 0.50 (middle), and 0.67 (bottom). Labels represent the experimental compositions shown in Table 1 . 

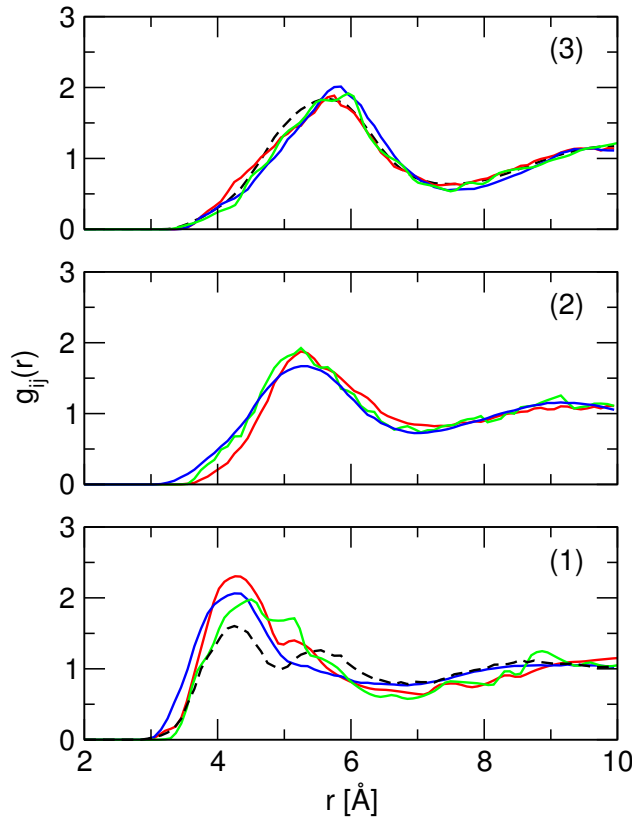

Fig. 5 Centre of mass radial distribution functions for (1) acetic acid-acetic acid, (2) pyridine-acetic acid, and (3) pyridine-pyridine from the EPSR models of the pyridine-acetic acid mixtures at $\chi_{\mathrm{HOAc}}=0.33$ (red), 0.50 (green), and 0.67 (blue) with the pure acetic acid and pyridine RDFs shown as black dashed lines in the respective plots.

\section{Pyridine}

A good fit of experimental and EPSR simulated structure factors for three isotopically distinct samples of pyridine (protiated, deuteriated and 50:50 mixture) was obtained (Figure 3 , top). The RDF reveals a well defined first shell centred around 5.6 $\AA$ with a minimum at 7.5 $\AA$. The average pyridinepyridine coordination number in the first shell is $10.1 \pm 1.6$ which compares favourably with previous MD simulations from Sagarik and Spohr ${ }^{34}$ who reported approximately 11 molecules in the first coordination shell.

The centre-of-mass spatial density function (SDF) for pyridine was calculated and is plotted in Figure 6 to show the top $20 \%$ probability of finding a pyridine atom around the central pyridine within the first coordination shell to $7.5 \AA$. The inhomogeneous distribution is revealed, with higher probability regions above and below the pyridine ring, which arise from $\pi$-orbital interactions and the ability of near neighbour molecules to approach closer to the centre of mass from these directions. Five lobes of higher probability are also evident around the plane of the pyridine ring. Four of these lobes roughly correspond to the positions of pairs of $\mathrm{H}-\mathrm{C}=\mathrm{C}-\mathrm{H}$ hydrogen atoms in the ring that are responsible for edge-toface Y-interactions between rings, as seen in the liquid structure of benzene. ${ }^{22}$ The fifth lobe appears to be centred on the

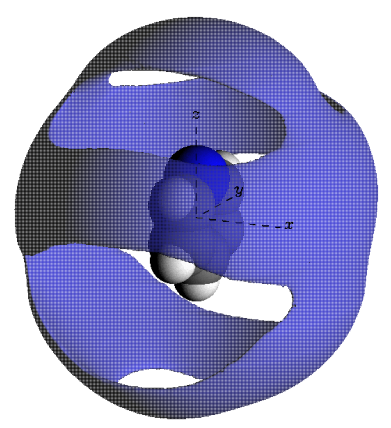

Fig. 6 Spatial density function for pyridine showing the top $20 \%$ probability within the first coordination sphere of pyridine (2.0-7.5 ̊).
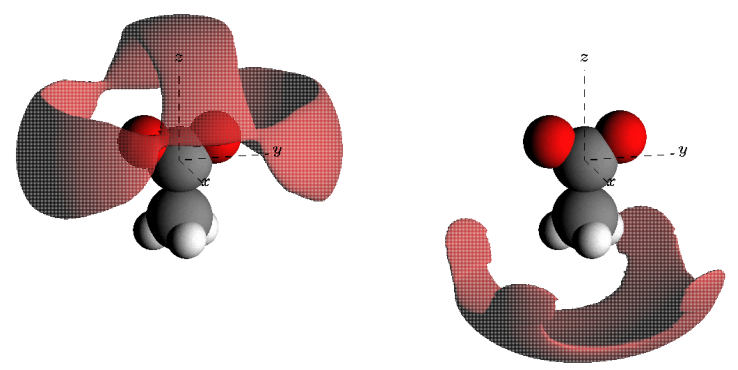

Fig. 7 Spatial density functions for acetic acid derived from the EPSR 'free proton' model, showing the top $25 \%$ probability of finding an acetate molecule at a distance between 2.0-5.0 $\AA$ (left) and 5.0-7.0 $\AA$ (right) from the centre of mass.

pyridine $\mathrm{N}$-lone pair, although there is no evidence of aggregation through $\mathrm{C}-\mathrm{H} \cdots \mathrm{N}$ interactions. An in-depth analysis of the pyridine-pyridine structure (e.g. angular distribution ring-ring correlations) is outside of the scope of this paper.

\section{Acetic Acid}

Imberti and Bowron ${ }^{24}$ have reported on a neutron scattering investigation of acetic and formic acids using a molecular (undissociated) descriptions to seed their EPSR model. The dissociation constant of pure acetic acid ${ }^{35}$ is in the order of $1.8 \times 10^{-5}$, therefore no dissociated protons were expected to be observed. Here, the outcomes of modelling acetic acid using a 'free-proton' model (with acetate and an unconstrained proton) are compared with the previous work ${ }^{24}$ in order to test the validity of this new approach.

Experimental structure factors for neat deuteriated, protiated and 1:1 H:D mixed acetic acid, the corresponding simulated data from EPSR and the residual differences between the experimental and model data sets are shown in Figure 3 (bottom). 
The site-site partial RDF for the free hydrogen $\left(\mathrm{H}_{\mathrm{F}}\right)$ to carboxylate oxygens $(\mathrm{O})$ is shown in Figure 8 and reveals a strong $\mathrm{O}-\mathrm{H}_{\mathrm{F}}$ correlation centred at $1.40 \AA$. This demonstrates that the 'free-proton' simulation model has responded to the experimental data input by generating an un-ionised, molecular representation of acetic acid. The $\mathrm{H}_{\mathrm{F}}-\mathrm{O}$ coordination number, $\mathrm{N}(\mathrm{r})$, as a function of distance is also shown in Figure 8. Under the first peak, the $\mathrm{H}_{\mathrm{F}}-\mathrm{O}$ coordination number, averaged over hundreds of configurations, was $2.38 \pm 0.87$, which is consistent with the formation of $\mathrm{O} \cdots \mathrm{H} \cdots \mathrm{O}$ hydrogen bonds. Imberti and Bowron ${ }^{24}$ derived a coordination number of 1.1-1.2 \pm 0.5 (to $r_{\max }=2.5 \AA$ ) for the acidic- $\mathrm{H} \cdots \mathrm{O}$, excluding the explicitly defined $\mathrm{O}-\mathrm{H}$ bond in their molecular description. Thus giving an average coordination number for the acetic acid hydrogen 2.1-2.2 \pm 0.5 . It is worth noting that a $\mathrm{H}_{\mathrm{F}}-\mathrm{O}$ coordination number $<1.0$ would reveal the presence of free protons in the model, which would conflict with the experimental dissociation constant for acetic acid ${ }^{35}$ and reveal fundamental inconsistencies between the solutions obtained using the two simulation models. This was not the case, and both models gave comparable results.

The acetic acid-acetic acid centre of mass RDF profile is shown in Figure 5 and reveals two maxima within the acetic acid local coordination environment at $c a .4 .4 \AA$ and $c a .5 .5$ $\AA$. The first peak reflects the formation of hydrogen-bonding between acetic acid molecules in the first shell, whereas a major contribution to the second peak is secondary correlation through the formation of oligomeric chains of molecules (which differs from gas-phase dimers) and is discussed later.

The association patterns for acetic acid molecules in the liquid state are revealed in the SDF plots (Figure 7), which show the probabilities of finding acetate groups between $r_{\min }$ and $r_{\text {max }}$ in different positions around a central acetate group. High probability density within the 2-5 A SDF around the carboxylate function is a result of $\mathrm{O} \cdots \mathrm{H}_{\mathrm{F}} \cdots \mathrm{O}$ hydrogen-bonding, and corresponds to the first peak in the acetate-acetate RDF (peak $\max$ at $4.4 \AA$ ). The postulated origin of the second peak in the acetate-acetate RDF at $5.5 \AA$ is confirmed by calculating the SDF over the range of 5.0-7.0 $\AA$, which shows this second region relates to hydrophobic association of the methyl groups.

Thus, starting with an ionic model for the liquid, comprising of protons and acetate anions, a molecular hydrogen-bonded description was obtained from the simulation model, with all features consistent with the previous molecular simulation. ${ }^{24}$ That is, with formation of extended hydrogen-bonded molecular acetic acid chains in the liquid state and with primary $\mathrm{O} \cdots \mathrm{H} \cdots \mathrm{O}$ and secondary $\mathrm{CH}_{3} \cdots \mathrm{CH}_{3}$ interactions contributing to the overall structure. This agreement indicates that the 'free proton' starting description for the EPSR simulation can respond effectively to the experimental data inputs and generate a self-consistent and realistic model of the liquid structure.

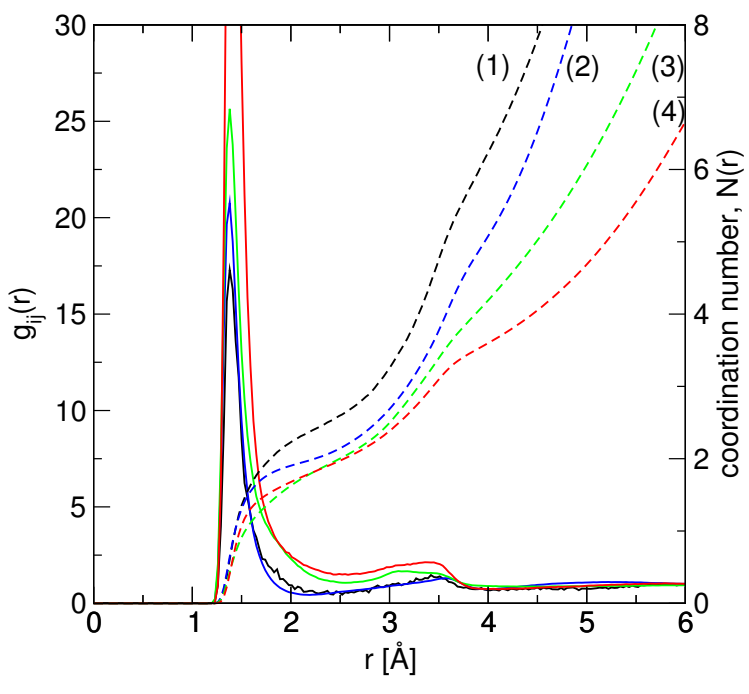

Fig. 8 Site-site partial distribution functions, $\mathrm{g}_{i j}(\mathrm{r})$, and cumulative coordination numbers, $\mathrm{N}(\mathrm{r})$, for hydrogen-oxygen $\left(\mathrm{H}_{\mathrm{F}}-\mathrm{O}\right)$ correlations calculated from the EPSR simulations of the acetic acid/pyridine mixtures at $\chi_{\mathrm{HOAc}}=1.00$ (1), 0.67 (2), 0.50 (3), and 0.33 (4). The strong correlation of the 'free proton' to carboxylate oxygens is indicative of the formation of non-ionised, molecular acetic acid. The $\mathrm{H}_{\mathrm{F}}-\mathrm{O}$ nearest neighbour coordination number under the first peak (maxima at $1.40 \AA$ ) is approximately 2 in all the systems, consistent with the formation of hydrogen-bonded bridges between acetic acid molecules. No measurable $\mathrm{H}_{\mathrm{F}}-\mathrm{N}$ correlation was observed in the systems.

\section{Pyridine-Acetic Acid Mixtures}

Neutron diffraction techniques have not previously been employed to investigate the liquid structure of pyridine-acetic acid mixtures. Mixtures with $\chi_{\mathrm{AcOH}}=0.33,0.50$, and 0.67 were examined, and experimental neutron scattering data for the H/D-isotopically substituted samples shown in Table 1 were collected. Using EPSR, the three compositions were modelled, refining the simulations against the experimental data sets (five each for $\chi_{\mathrm{AcOH}}=0.33$ and 0.67 , and seven for $\left.\chi_{\mathrm{AcOH}}=0.50\right)$ using simulation boxes constructed from the appropriate composition mixtures of pyridine and 'free' proton acetic acid, as described above. Again, in each case, good agreement between the experimental data and the EPSRderived models for the mixtures was obtained (Figure 4).

The $\mathrm{H}_{\mathrm{F}}-\mathrm{O}$ correlation present in acetic acid as a peak at $1.40 \AA$ in the $\mathrm{H}_{\mathrm{F}}-\mathrm{O}$ partial RDF plot is retained in all the mixtures (Figure 8), indicating the presence of molecular acetic. The $\mathrm{H}_{\mathrm{F}}$ coordination number over the separation range 1.0 $2.5 \AA$ is $c a .2$ in each case. This is slightly lower than that of the pure acetic acid and decreases slightly with decreasing $\chi_{\text {HOAc }}$ indicating that chains persist throughout all the studied compositions, although the 'cross-correlation' between acid chains decreases due to a net dilution of acetic acid in the 
mixtures. No measurable degree of $\mathrm{H}_{\mathrm{F}} \cdots \mathrm{N}$ association was observed over comparable distances in the models, determined by calculating the average $\mathrm{N}-\mathrm{H}_{\mathrm{F}}$ coordination number for the pyridine molecules over hundreds of configurations. Demonstrably, pyridine is not protonated to a measurable degree even with a large excess of acetic acid $\left(\chi_{\mathrm{HOAc}}=0.67\right)$.

Acetate-acetate, acetate-pyridine, pyridine-pyridine RDFs calculated from the EPSR simulations of the mixtures are compared with those for pure acetic acid and pyridine in Figure 5. In all the mixtures, the pyridine-pyridine RDF is similar to that of pure pyridine, and retains the first shell correlation at $5.2 \AA$. Similarly, the pyridine-acetate RDFs show a first shell peak at $5.6 \AA$ which remains invariant with composition. This suggests that the overall interaction profile between pyridine and acetic acid is independent of the studied compositional range, and that variations in physical properties ${ }^{7,8}$ arise from changes in the association of acetic acid molecules. Indeed, in contrast to the pyridine-pyridine and pyridine-acetate RDFs, the acetate-acetate RDFs (Figure 5) show a sequential change in the profile of the first correlation peak (3.0-7.0 $)$ as a function of composition. Compared to the RDF profile for pure acetic acid, the feature at $c a .4 .0 \AA$ (corresponding to hydrogen-bonded bridges) increases in intensity, whereas the feature at $c a$. $5.5 \AA$ decreases in intensity. Since the short $\mathrm{H}_{\mathrm{F}}-\mathrm{O}$ correlation is retained across all compositions (Figure 8), these differences can not arise from changes in the central motif of hydrogen-bonded acetic acid chains and consequently must derive from reduction or loss of secondary correlation in, and between, chains.

Radial distribution functions plotted in Figure 9 show the changes in correlation between the two carbon sites of acetic acid with composition in the mixtures. The carboxylate $\mathrm{C}_{\mathrm{A} 2}-\mathrm{C}_{\mathrm{A} 2} \mathrm{RDF}$ is similar to that for the acetate-acetate centre of mass RDF and shows the same two maxima at $c a .4 .5$ and $5.5 \AA$ for $\chi_{\mathrm{HOAc}}=1.00$ which are at appropriate lengths to correspond to $a-b$ and $a-c$ correlations along hydrogenbonded (-a-b-c-) chains. The methyl-methyl $\mathrm{C}_{\mathrm{A} 1}-\mathrm{C}_{\mathrm{A} 1}$ correlation in neat acetic acid also shows a well defined maximum at $c a .4 .0 \AA$ which appears consistent with intra-strand close contact of hydrophobic methyl groups at the van der Waals radius. On going to pyridine-acetic acid mixtures, the short distance $\mathrm{C}_{\mathrm{A} 1}-\mathrm{C}_{\mathrm{A} 1}$ correlation moves out into a broader maxima centred at $c a .4 .8 \AA$ while, as described above, the two peaks for the $\mathrm{C}_{\mathrm{A} 2}-\mathrm{C}_{\mathrm{A} 2}$ correlation coalesce. Running coordination numbers, as a function of distance, for the corresponding $\mathrm{C}-\mathrm{C}$ correlations are also shown in Figure 9. Coordination numbers (Table 5) summed to $r_{\max }=6.5 \AA$, the minimum in the RDFs after the first peak, show a monotonic decrease in the average coordination numbers with decreasing $\chi_{\mathrm{HOAc}}$ from $c a .10 .8$ at $\chi_{\mathrm{HOAc}}=1.00$ to 3.5 at $\chi_{\mathrm{HOAc}}=0.33$.

A picture of the coordination shells around each component in the liquid can be constructed by comparing the site-site and

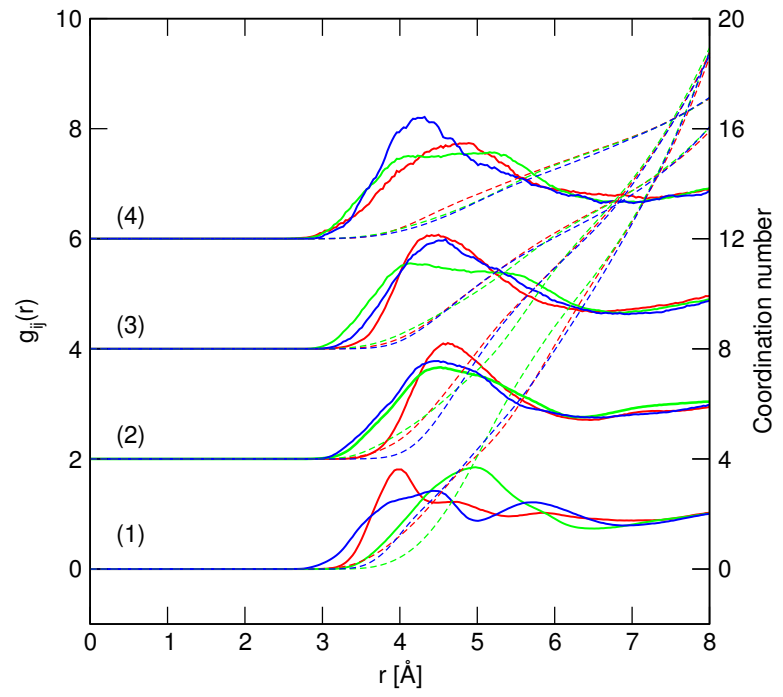

Fig. 9 Plot of carbon-carbon rdfs and corresponding coordination numbers for acetic acid from the simulation models with $\chi_{\mathrm{HOAc}}=$ 1.00 (1), 0.67 (2), 0.50 (3) and 0.33 (4) showing the methyl carbon-methyl carbon $\left(\mathrm{C}_{\mathrm{A} 1}-\mathrm{C}_{\mathrm{A} 1}\right)$ correlation in red, carboxylate-carboxylate carbons $\left(\mathrm{C}_{\mathrm{A} 2}-\mathrm{C}_{\mathrm{A} 2}\right)$ in blue, and the $\mathrm{C}_{\mathrm{A} 1}-\mathrm{C}_{\mathrm{A} 2}$ cross correlation in green.

centre of mass RDFs. The first coordination shell of pyridine contains both pyridine and acetic acid, as shown by the first shell peaks centred around $5.2 \AA$ (pyridine-acetate) and $5.6 \AA$ (pyridine-pyridine) in Figure 5. The $\mathrm{H}_{\mathrm{F}}$-pyridine RDF shows only a broad, low intensity feature at $5.0 \AA$, consistent with the absence of significant hydrogen-transfer or acid-base pairing. Similarly, there is no evidence of interaction between pyridine and the $\mathrm{H}_{\mathrm{F}}$ proton from the $\mathrm{N}-\mathrm{H}$ site-site correlation function. However the SDF (for $\chi_{\mathrm{HOAc}}=0.50$, in Figure 10 and discussed below) does show that the highest probability for locating the $\mathrm{H}_{\mathrm{F}}$ hydrogen around a central pyridine is in the general region of the $\mathrm{N}$-atom.

SDFs were calculated from the EPSR simulation for the $\chi_{\mathrm{HOAc}}=0.50$ pyridine-acetic acid mixture. Acetate-pyridine, pyridine-acetate and pyridine- $\mathrm{H}_{\mathrm{F}}$ SDFs are shown in Figure 10. The acetate-acetate correlations covering the 2.0-5.0 and 5.0-7.0 ̊ range can be compared to those found for pure acetic acid in Figure 7, and the pyridine-pyridine correlations can be compared to neat pyridine from Figure 6 . The overall shape and positions of the acetate-acetate correlations at $\chi_{\mathrm{OAc}}$ $=0.50$ appear similar to that in pure acetic acid. The preference for acetate near-neighbours to interact most strongly through $\mathrm{O} \cdots \mathrm{H} \cdots \mathrm{O}$ hydrogen bonding is evident in the 2.0 $5.0 \AA$ SDF. The strongest acetate-acetate correlations are associated with the carboxylate groups, which is consistent with the $\mathrm{H}_{\mathrm{F}}-\mathrm{O}$ partial radial distribution functions (Figure 8). The longer range correlation through the $-\mathrm{CH}_{3}$ group, shown in 

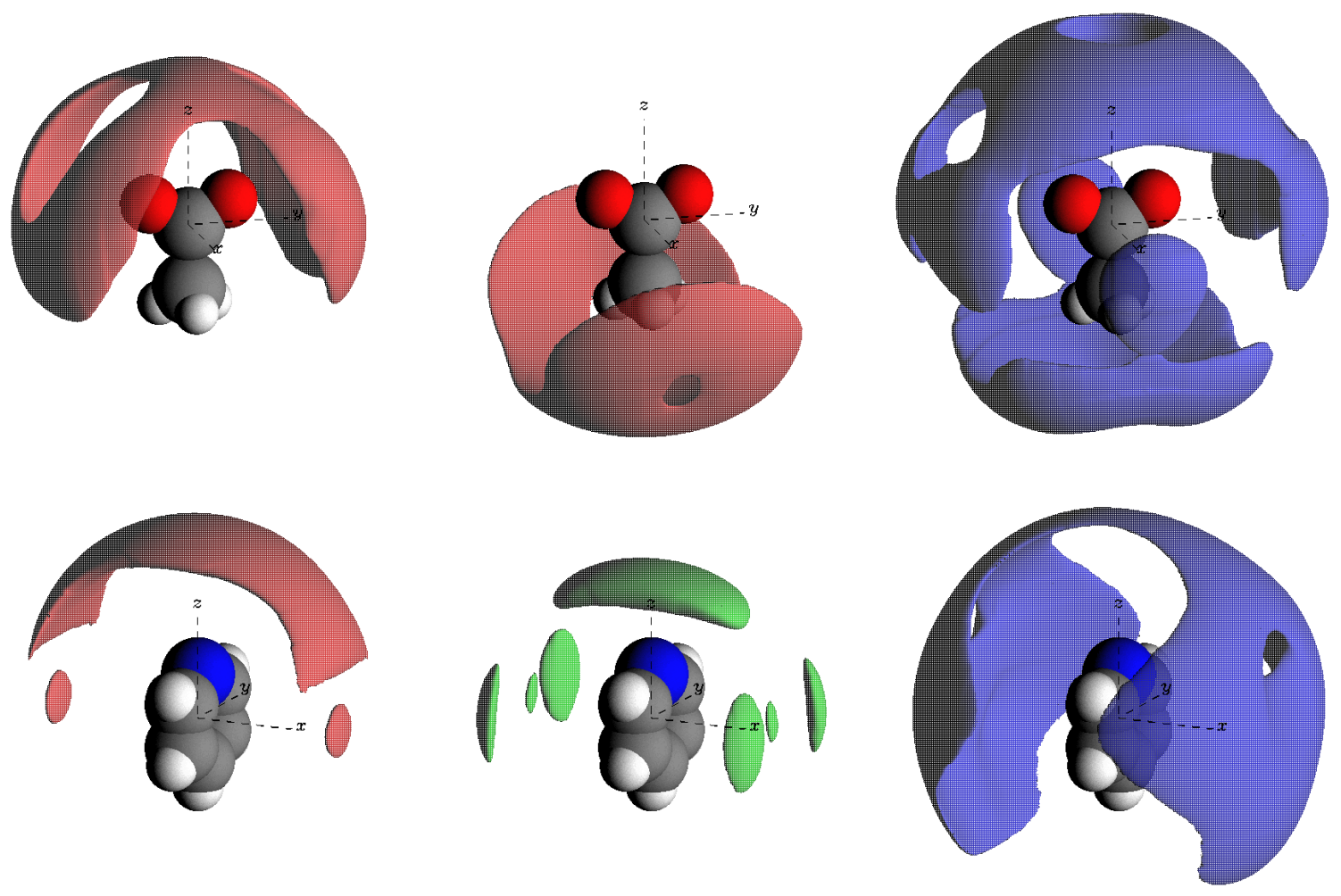

Fig. 10 Spatial density functions for 1:1 acetic acid:pyridine mixture derived from the EPSR 'free proton' model. Top from left to right: acetate around acetate depicting probability within the range 3.0-5.0 $\AA$, acetate around acetate depicting probability within the range

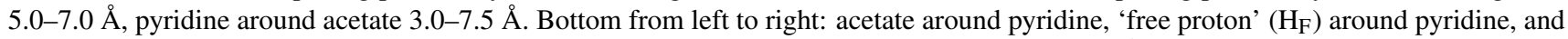
pyridine around pyridine. All plots depict the regions within the first coordination shell (3.0-7.50 $⿱$ ) as shown in the RDFs, where the probability of finding a second species is greater than $20 \%$.

the acetate-acetate 5.0-7.0 ̊ SDF, becomes more diffuse and less structured compared to the pure acid. The SDF describing pyridine in the acetate first shell shows a largely unstructured and diffuse probability distribution associated with both the carboxylate and methyl groups.

Pyridine-centred SDFs show both pyridine and acetic acid in the first coordination shell (with maxima at 5.6 and $5.1 \AA$ respectively). Compared to pure pyridine (Figure 6), the pyridine-pyridine correlation in Figure 10 is more disordered and less structured, although the maximum probability regions still remain above and below the pyridine ring plane associated with $\pi$-orbital interactions, and as a band around the heteroatom. The probability of finding acetic acid within the first coordination shell of pyridine shows a much greater orientational preference. A band of density forms an arc associated with the $\mathrm{N}$-atom. Probing specifically for $\mathrm{H}_{\mathrm{F}}$-pyridine correlations, the acidic $\mathrm{H}_{\mathrm{F}}$ hydrogen also appears preferentially associated with the heteroatom, suggesting a weak acid-base interaction, although at concentrations too low to reveal detail in the RDFs. Presumably, this correlation relates to pyri- dine association with the terminal groups of hydrogen-bonded acetic acid chains.

The presence of these hydrogen-bonded acetic acid chains, distributed throughout the liquids, can be clearly observed in snapshots taken from the EPSR simulations (Figure 11). At a qualitative level, the chains appear to decrease in length as $\chi_{\mathrm{OAc}}$ in the mixtures decreases, although, it is important to note that these figures provide no information regarding the persistence length for any given chain. Probabilities of finding hydrogen-bonded acetic acid chains of a certain size have been calculated, using a maximum intermolecular $\mathrm{O}-\mathrm{O}$ separation of a hydrogen-bonded pair allowed for inclusion in a chain of $2.5 \AA$. The results are plotted in Figure 12. In pure acetic acid, long chains of up to 20 acetic acid units were observed. Confirming the qualitative deductions from Figure 12, the oligomer distribution and average size decreases as $\chi_{\mathrm{HOAc}}$ decreases. At $\chi_{\mathrm{HOAc}}=0.33$, most acetic acid molecules are involved in the formation of dimers and trimers.

The structural model obtained from the neutron scattering experiments and analysis appears to support a liquid struc- 

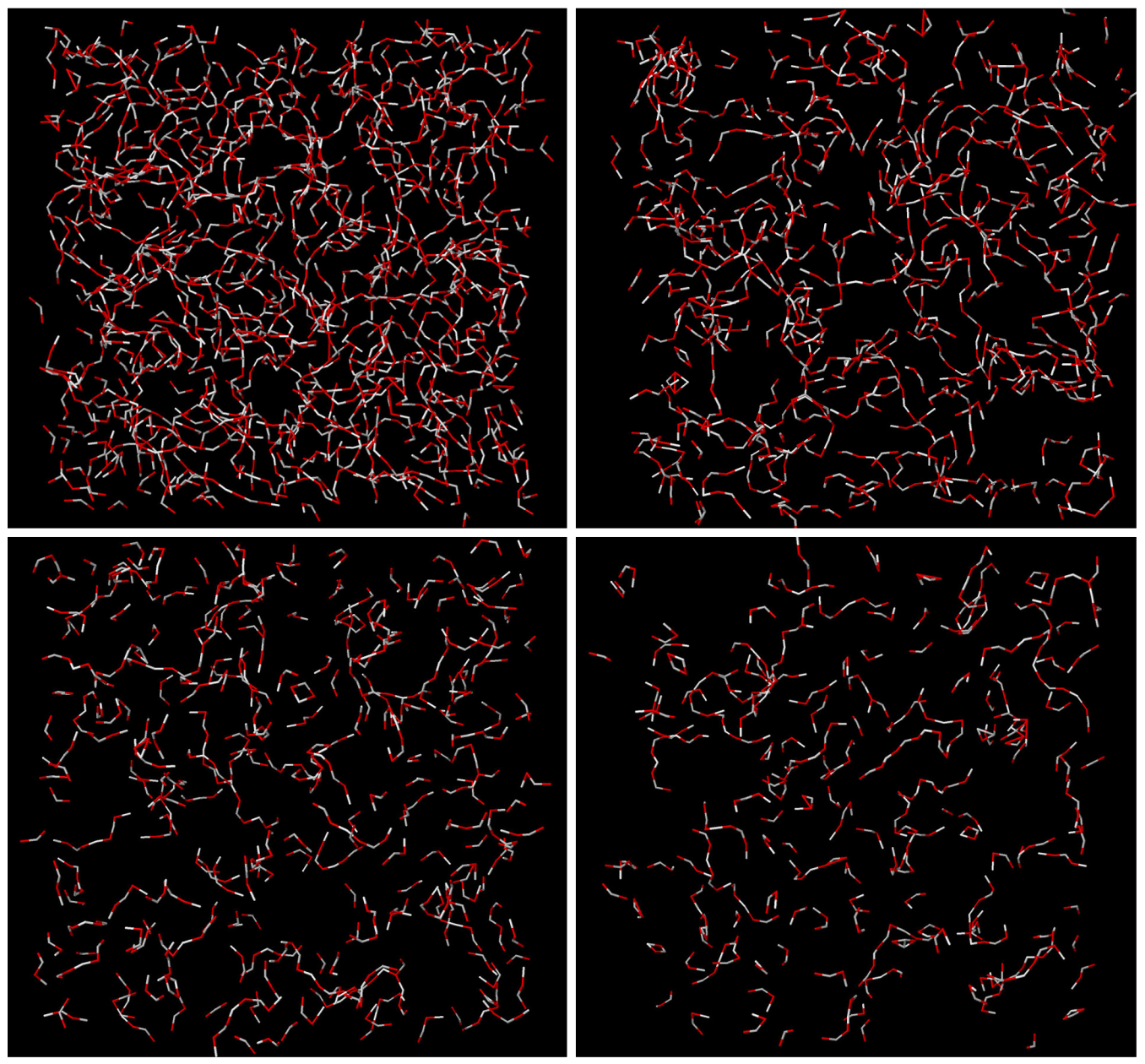

Fig. 11 Snapshots from the EPSR simulations of the $\chi_{\mathrm{HOAc}}=1.00$ (top left), 0.67 (top right), 0.50 (bottom left), and 0.33 (bottom right) systems showing only the chain-forming atoms from acetic acid $(\mathrm{C}-\mathrm{O} \cdots \mathrm{H} \cdots \mathrm{O}-\mathrm{C})$ and revealing a qualitative decrease in average chain length as $\chi_{\mathrm{HOAc}}$ is reduced.

ture comprising of oligomeric hydrogen-bonded acetic acid chains and, although no strong ion pairing was directly observed, association of carboxylic acid sites with the basic Natom of pyridine, as shown by the $\mathrm{H}_{\mathrm{F}}$-pyridine SDF in Figure 10. Based on the conclusions from Johansson et al. ${ }^{12}$ that oligomeric acid clusters can have greater acidity than acid monomers due to the charge delocalisation, it seems likely that acid-base association should occur most readily in mixtures containing the largest oligomer chains. That is, when $\chi_{\text {HOAc }}$ is large.

The significant difference in the acetic acid RDFs between the mixtures and pure acetic acid is the reduction in the interchain cross correlation, evidenced by the collapse of the $5.5 \AA$ peak in the acetic acid-acetic acid RDF, Figure 5 and the increased diffusivity of the acetate-pyridine SDF correlation between 5-7 $\AA$ in Figure 10. Physical dilution of oligomeric clusters on addition of pyridine, and promotion of larger clusters at relatively low mole fractions of pyridine may explain the liquid behaviour, especially the ability to form large oligomeric clusters with greater acidity than bulk acetic acid enabling maximum ion pair interactions from terminal acid groups to pyridine at $\chi_{\mathrm{HOAc}}=0.83$.

\section{Validity of the 'free proton' model}

Because liquid systems are inherently disordered, there is not necessarily just one model that can fit the experimental data. The free proton approach, as described here, was chosen in order to reduce prejudice in the simulations based on a priori assumptions about speciation. The results show that this approach to pyridine-acetic acid mixtures generates a model for the liquid hydrogen-bonded acetic acid oligomers that fits the experimental data, and is consistent with that generated previously with EPSR for acetic acid using an undissociated model 
Table 5 Coordination numbers for the acetic acid $\mathrm{C}-\mathrm{C}$ pair correlation functions, calculated to $r_{\max }$, the minimum after the first peak in the corresponding radial distribution functions, for the acetic acid-pyridine mixtures of composition $\chi_{\mathrm{HOAc}}=1.00-0.33$.

\begin{tabular}{lllr}
\hline Pair & $\chi_{\mathrm{HOAc}}$ & $r_{\max }$ & $n\left(r_{\max }\right)$ \\
\hline $\mathrm{C}_{\mathrm{A} 1}-\mathrm{C}_{\mathrm{A} 1}$ & 1.00 & 6.5 & $10.5 \pm 1.6$ \\
& 0.67 & 6.5 & $6.8 \pm 1.9$ \\
& 0.50 & 6.5 & $4.7 \pm 1.6$ \\
$\mathrm{C}_{\mathrm{A} 2}-\mathrm{C}_{\mathrm{A} 2}$ & 0.33 & 6.5 & $3.0 \pm 1.4$ \\
& 0.67 & 6.5 & $10.4 \pm 1.6$ \\
& 0.50 & 6.5 & $7.3 \pm 2.2$ \\
$\mathrm{C}_{\mathrm{A} 1}-\mathrm{C}_{\mathrm{A} 2}$ & 0.33 & 6.5 & $4.9 \pm 1.6$ \\
& 1.00 & 6.5 & $11.6 \pm 1.5$ \\
& 0.67 & 6.5 & $7.8 \pm 2.1$ \\
& 0.50 & 6.5 & $5.9 \pm 1.6$ \\
& 0.33 & 6.5 & $4.1 \pm 1.5$ \\
\hline
\end{tabular}

by Imberti and Bowron ${ }^{24}$.

This does not, per se, disprove the validity of different models. Unsurprisingly, a comparable liquid structure was revealed when the data was modelled as an undissociated mixture of the two components. As discussed, such a model would not allow potential ionisation to be revealed, simulation with the free proton methodology allows more flexibility to the system. Using a fully dissociated description of the liquids, containing pyridinium and acetate ions, after Venkatesan and Suryanarayana, ${ }^{8}$ resulted in a poor fit to the experimental data in the the low $Q$ region of the spectra below ca. $0.9 \AA^{-1}$. This can be interpreted in terms of the simulation trying to impose a degree of intermediate range order on the model to account for Coulombic attractive forces present between the cations and anions of this model that are absent from the molecular description.

However, the free-proton model still retains a degree of constraint that may drive the model through, for example through the selection of reference potentials applied to the components, especially charge on the acetate which will necessarily vary and be modulated by changes in association. Within this context, it is important to note that the free proton is only one of approximately eighteen atoms and one of eight hydrogens (for $\chi_{\mathrm{HOAc}}=0.50$, varying with composition). The effect of this single proton site on the structure factor approaches the limits of sensitivity for neutron scattering techniques. Consequently, it is important to tension the results with comparative simulations fitting with, for example fully dissociated and undissociated configurations, in order to differentiate between structural contributions that arise from the simulation model or directly from site-site interactions.

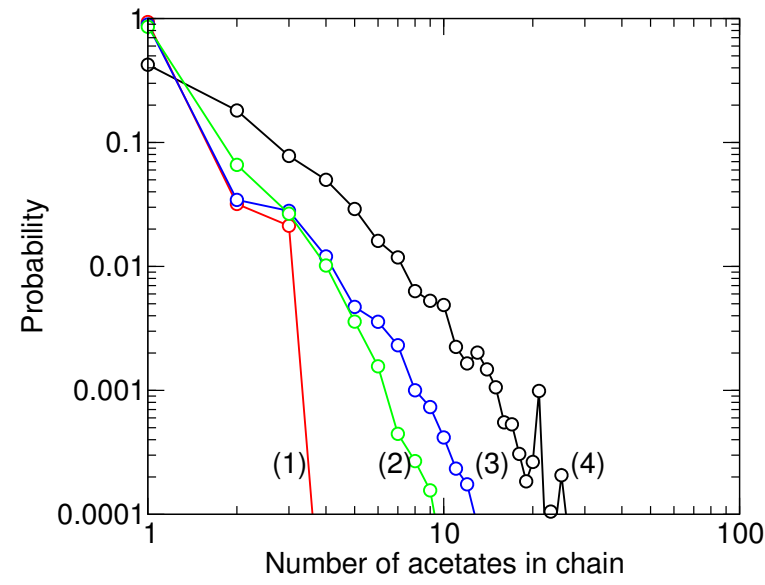

Fig. 12 Probability of finding chains of acetic acids of a certain size in the EPSR models of acetic acid/pyridine mixtures with $\chi_{\mathrm{HOAc}}=$ 0.33 (1), 0.50 (2), 0.67 (3), and 1.00 (4). The maximum separations for acetates within the same chain was is based on a 'shortest path' criteria of less than $3 \AA$ separation of $\mathrm{O}$ atoms on adjacent acetates (connected through $\mathrm{O} \cdots \mathrm{H} \cdots \mathrm{O}$ hydrogen bonding).

\section{Conclusions}

The liquid structure of pyridine-acetic acid mixtures of compositions $\chi_{\mathrm{HOAc}}=0.33,0.50$, and 0.67 has been investigated using neutron diffraction combined with EPSR modelling for mixtures and compared to pure pyridine and acetic acid. Using a 'free proton' model for acetic acid in the systems, a description of the liquid structure are obtained in which all the acetic acid is in a molecular state forming oligomeric chains through $\mathrm{C}-\mathrm{O} \cdots \mathrm{H} \cdots \mathrm{O}-\mathrm{C}$ hydrogen-bonding. The size of the oligomer chains increases with $\chi_{\mathrm{HOAc}}$ and in pure acetic acid, a methylmethyl cross-chain correlation between oligomer strands is also observed, and is absent (or significantly reduced) in the mixtures. There is little evidence for proton-transfer or ion pairing between pyridine and acetic acid in the modelled liquid structure at any of the compositions investigated although, in the models described here, the highest probability of acetic acid correlation with pyridine was observed in the region of the $\mathrm{N}$-atom of pyridine suggesting that transient association was occurring in the liquids, presumably from terminal acid groups of H-bonded chains. This contrasts with the fully ionised description of the systems presented by Venkatesan and Suryanarayana, ${ }^{8}$ and also with the results from solution studies ${ }^{9-11}$ where discrete acid-base clusters were reported.

The ability of the 'free proton' ionic description to model and reproduce the covalent molecular structure of these systems, driven by fitting to the multiple experimental data sets from H/D isotopically substituted samples, provides a flexible approach to explore the liquid structure of acid/base mixtures without biasing the simulations with input of speciation infor- 
mation and, as such, should be ideally suitable to the study of acid/base mixtures with greater $\Delta \mathrm{p} K_{\mathrm{a}}$ and intermediate degrees of proton transfer and ionicity.

\section{Acknowledgements}

We thank QUILL and the Department of Education and Learning in Northern Ireland (DEL) for PhD studentships (to CW and AHT respectively). We also thank the Science and Technology Facilities Research Council (STFC) for beam-time on SANDALS (ISIS experiments RB1310009 and RB1320357).

\section{References}

1 C. Hardacre, J. D. Holbrey, M. Nieuwenhuyzen and T. G. A. Youngs, Acc. Chem. Res., 2007, 40, 1146-1155.

2 T. G. A. Youngs, J. D. Holbrey, C. L. Mullan, S. E. Norman, M. C. Lagunas, C. D'Agostino, M. D. Mantle, L. F. Gladden, D. T. Bowron and C. Hardacre, Chem. Sci., 2011, 2, 1594-1605.

3 J. Estager, J. D. Holbrey and M. Swadźba-Kwaśny, Chem. Soc. Rev., 2014, 43, 847-886.

4 K. Matuszek, A. Chrobok, F. Coleman, K. R. Seddon and M. SwadźbaKwaśny, Green Chem., 2014, 16, 3463-3471.

5 W. Ramsay, Philosophical Magazine, 1876, 5, 269-281.

6 P. Walden, Bull. Acad. Imper. Sci., 1914, 405-422.

7 (a) L. E. Swearingen and L. B. Heck, J. Phys. Chem., 1934, 38, 395-400; (b) L. E. Swearingen and R. F. Ross, J. Phys. Chem., 1935, 39, 821-828.

8 (a) V. K. Venkatesan and C. V. Suryanarayana, Nature, 1956, 178, 13451346; (b) V. K. Venkatesan and C. V. Suryanarayana, J. Phys. Chem., 1956, 60, 777-779.

9 (a) N. S. Golubev, S. N. Smimov, V. A. Gindin, G. S. Denisov, H. Benedict and H.-H. Limbach, J. Amer. Chem. Soc., 1994, 116, 12055-12056; (b) N. S. Golubev, G. S. Denisov, S. N. Smirnov, D. N. Shchepkin and H.-H. Limbach, Z. Physik. Chem., 1996, 196, 73-84; (c) S. N. Smirnov, N. S. Golubev, G. S. Denisov, H. Benedict, P. Schah-Mohammedi and H.-H. Limbach, J. Amer. Chem. Soc., 1996, 118, 4094-4101.

10 R. Langner and G. Zundel, J. Chem. Soc., Faraday Trans., 1995, 91, 3831-3838.

11 G. M. Barrow, J. Amer. Chem. Soc., 1956, 78, 5802-5806.

12 K. M. Johansson, E. I. Izgorodina, M. Forsyth, D. R. MacFarlane and K. R. Seddon, Phys. Chem. Chem. Phys., 2008, 10, 2972-2978.

13 C. A. Angell, N. Byrne and J.-P. Belières, Acc. Chem. Res., 2007, 40, $1228-1236$.

14 J. Stoimenovski, D. R. MacFarlane, K. Bica and R. D. Rogers, Pharm. Res., 2010, 27, 521-526.

15 H. E. Fischer, A. C. Barnes and P. S. Salmon, Rep. Prog. Phys., 2006, 69, 233-299.

16 A. Soper, Mol. Phys., 2001, 99, 1503-1516.

17 J. Finney and A. Soper, Chem. Soc. Rev., 1994, 23, 1-10.

18 A. K. Soper, Chem. Phys., 2000, 258, 121-137.

19 (a) R. Leberman and A. K. Soper, Nature, 1995, 378, 364-366; (b) R. Mancinelli, A. Botti, F. Bruni, M. A. Ricci and A. K. Soper, Phys. Chem. Chem. Phys., 2007, 9, 2959-2967; (c) R. Hargreaves, D. T. Bowron and K. Edler, J. Amer. Chem. Soc., 2011, 133, 16524-16536.

20 (a) S. Biggin and J. E. Enderby, J. Phys., C, 1981, 14, 3129-3136; (b) F. G. Edwards, J. E. Enderby, R. A. Howe and D. I. Page, J. Phys., C, 1975, 8, 3483-3490.

21 (a) I. Petri, P. Salmon and H. Fischer, Phys. Rev. Lett., 2000, 84, 24132416; (b) P. S. Salmon, P. Roy. Soc.-Math. Phys. Sci., 1994, 445, 351-365.
22 T. F. Headen, C. Howard, N. T. Skipper, M. Wilkinson, D. T. Bowron and A. K. Soper, J. Amer. Chem. Soc., 2010, 132, 5735-5742.

23 (a) D. T. Bowron, J. L. Finney and A. K. Soper, J. Phys. Chem. B, 1998, 102, 3551-3563; (b) D. T. Bowron, J. L. Finney and A. K. Soper, Mol. Phys., 1998, 93, 531-543; (c) J. J. Towey, A. K. Soper and L. Dougan, J. Phys. Chem. B, 2012, 116, 13898-13904; (d) J. J. Towey, A. K. Soper and L. Dougan, Faraday Discuss., 2013, 167, 159-176.

24 S. Imberti and D. T. Bowron, J. Phys. Cond. Mat., 2010, 22, 404212.

25 R. Hayes, S. Imberti, G. G. Warr and R. Atkin, Phys. Chem. Chem. Phys., 2011, 13, 3237-3247.

26 (a) D. T. Bowron, C. D'Agostino, L. F. Gladden, C. Hardacre, J. D. Holbrey, M. C. Lagunas, J. McGregor, M. D. Mantle, C. L. Mullan and T. G. A. Youngs, J. Phys. Chem. B, 2010, 114, 7760-7768; (b) R. Hayes, S. Imberti, G. G. Warr and R. Atkin, Angew. Chemie Int. Ed., 2013, 52, 4623-4627; (c) R. Hayes, S. Imberti, G. G. Warr and R. Atkin, Phys. Chem. Chem. Phys., 2011, 13, 13544-13551; (d) C. Hardacre, J. D. Holbrey, C. L. Mullan, M. Nieuwenhuyzen, T. G. A. Youngs and D. T. Bowron, J. Phys. Chem. B, 2008, 112, 8049-8056; (e) C. Hardacre, J. D. Holbrey, S. E. J. McMath, D. T. Bowron and A. K. Soper, J. Chem. Phys., 2003, 118, 273-278.

27 (a) M. Deetlefs, C. Hardacre, M. Nieuwenhuyzen, O. Sheppard and A. K. Soper, J. Phys. Chem. B, 2005, 109, 1593-1598; (b) C. Hardacre, J. D. Holbrey, C. L. Mullan, M. Nieuwenhuyzen, T. G. A. Youngs, D. T. Bowron and S. J. Teat, Phys. Chem. Chem. Phys., 2010, 12, 1842-1853; (c) T. G. A. Youngs, C. Hardacre and J. D. Holbrey, J. Phys. Chem. B, 2007, 111, 13765-13774; (d) T. G. A. Youngs, J. D. Holbrey, M. Deetlefs, M. Nieuwenhuyzen, M. F. C. Gomes and C. Hardacre, ChemPhysChem, 2006, 7, 2279-2281; (e) R. Hayes, S. Imberti, G. G. Warr and R. Atkin, Angew. Chemie Int. Ed., 2012, 51, 7468-7471; ( $f$ ) J. Jacquemin, M. Bendova, Z. Sedlakova, M. Blesic, J. D. Holbrey, C. L. Mullan, T. G. A. Youngs, L. Pison, Z. Wagner, K. Aim, M. F. C. Gomes and C. Hardacre, ChemPhysChem, 2012, 13, 1825-1835; ( $g$ ) T. Murphy, R. Hayes, S. Imberti, G. G. Warr and R. Atkin, Phys. Chem. Chem. Phys., 2014, 16, 13182-13190; (h) A. H. Turner and J. D. Holbrey, J. Solution Chem., 2015 , in press.

28 V. N. Emel'yanenko, G. Boeck, S. P. Verevkin and R. Ludwig, Chem. Eur. J., 2014, 20, 11640-11645.

29 A. Botti, F. Bruni, M. A. Ricci and A. K. Soper, J. Chem. Phys., 2006, 125, 014508 .

30 A. K. Soper, GudrunN and GudrunX: Programs for correcting raw neutron and X-ray diffraction data to differential scattering cross section, RAL-TR-2011-013, Rutherford Appleton Laboratory technical report, 2011.

31 A. K. Soper, Chem. Phys., 1996, 202, 295-306.

32 Y. Zhang and E. J. Maginn, J. Phys. Chem. B, 2012, 116, 10036-10048.

33 M. W. Schmidt, K. J. Baldridge, J. A. Boatz, S. T. Elbert, M. S. Gordon, J. H. Jensen, S. Koseki, N. Matsunaga, K. A. Nguyen, S. J. Su, T. L. Windus, M. Dupuis and J. A. Montgomery, J. Comput. Chem., 1993, 14, 1347-1363.

34 K. Sagarik and E. Spohr, Chem. Phys., 1995, 199, 73-82.

35 E. J. Cohn, F. F. Heyroth and M. F. Menkin, J. Amer. Chem. Soc., 1928, 50, 696-714.

12 | Journal Name, 2010, [vol], 1-12 